
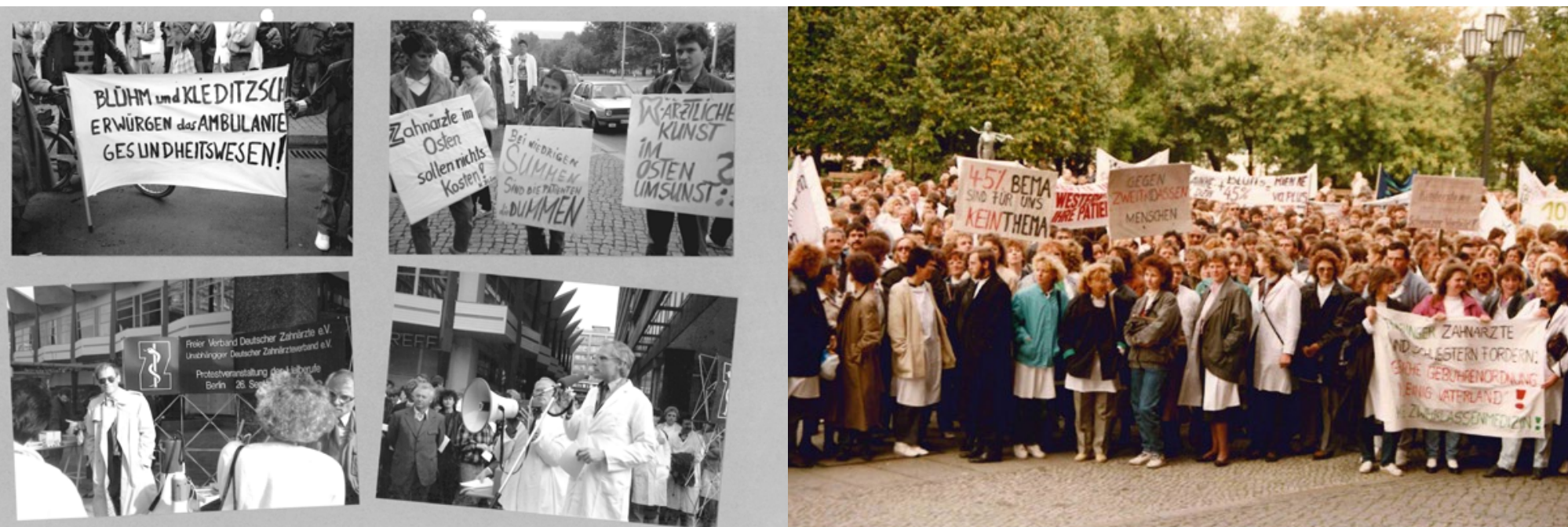

Der Aufbruch ostdeutscher Zahnärzte - 1989/90

\title{
Aus zwei mach eins
}

Ostdeutschlands Zahnärzte sind nach dem Wendejahr 1989 im Aufbruch. Nach der Abschaffung der Planwirtschaft und einem rein sozialistischen Gesundheitssystem streben sie nach Eigenständigkeit. Schon im Januar 1990 legen sie den Grundstein für den Unabhängigen Deutschen Zahnärzteverband (UDZ).

Ein kleine Gruppe Zahnärzte aus Leipzig und Taucha hatte zu einem ersten Diskussionsabend eingeladen, denn die Zukunft für DDR-Zahnärzte ist ungewiss. Viele der 12.000 ostdeutschen Zahnärzte wollen gern dem Vorbild der westdeutschen Kollegen folgen und sich niederlassen. Die Voraussetzungen dafür sind allerdings noch nicht geschaffen. Die Polikliniken, in denen die meisten von ihnen bis dahin gearbeitet hatten, werden allmählich abgewickelt. Bereits zur Gründung UDZ wird eine Zusammenarbeit mit dem Freien Verband vereinbart, da in Ost wie West der Kampf gegen dirigistische Eingriffe in die freie Berufsausübung der gleiche ist. Der UDZ hat regen Zulauf. Nur vier Monate nach der Gründung im März 1990 sind rund 6000 Zahnärzte - etwa die Hälfte aller ostdeutschen Kollegen - in dem neuen Verband vertreten. Von einer weiteren Ost-WestTeilung halten die Verbandsvertreter hüben wie drüben nicht viel, denn es ist klar, dass nur gemeinsam mehr Schlagkraft entwickelt werden kann. Kurz nach der Wiedervereinung von Bundesrepublik und DDR vereinen sich auch die beiden zahnärztlichen Berufsverbände. Die Erwartung liegt vor allem darin, für alle deutschen Zahnärzte die gleichen Arbeitsbedingungen $\mathrm{zu}$ schaffen. Dafür waren die ostdeutschen Zahnärzte bereits massenweise auf die Straße gegangen. Die Gleichheit in der Einheit allerdings blieb ein Ziel, das sich so schnell nicht erfüllte.

Der gemeinsame Protest gegen das GKV-System läuft in dieser Zeit auf Hochtouren. In einer Grundsatzentscheidung entschließt sich der FVDZ zu einem Ausstieg aus der GKV und sagt dem Sachleistungssystem den Kampf an - dies geht bis zur Drohung der Zahnärzte, die Kassenzulassung zurückzugeben. Die
Politik begegnet den „aufständischen“ Zahnärzten mit Drohungen, redet von „Behandlungsboykott“. Der FVDZ bleibt jedoch bei seiner Position, dass niemand unbegrenzte Leistungen für begrenzte Mittel verlangen kann und vertritt die Überzeugung, dass nicht alles medizinisch Machbare von der Solidargemeinschaft getragen werden könne.

sas

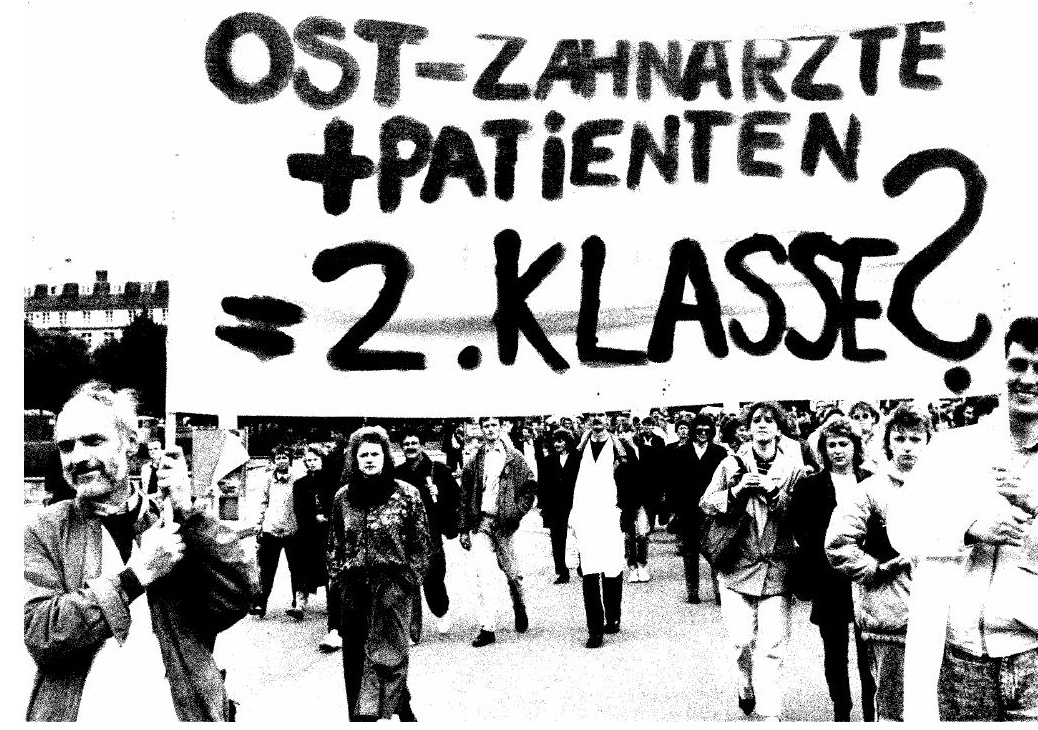

